\title{
Proceeding
}

Supplementary Issue: Spring Conferences of Sports Science. International Conference on Psychology of Education Sciences \& Lifestyle.

\section{Effect of global postural correction exercises on stress urinary incontinence during pregnancy: A randomized controlled trial}

\author{
ASMAA M. EL BANDRAWY ${ }^{1}$, MOHAMMED NAEEM MOHAMED², HOSSAM ALDIN H. KAMAL ${ }^{3}$, HAMADA \\ AHMED HAMADA 4 , RAMI ABBAS ${ }^{5}$, MARWA ABD EL-RAHMAN MOHAMED ${ }^{1}$ \\ ${ }^{1}$ Department of Woman's Health, Faculty of Physical Therapy, Cairo University, Egypt \\ ${ }^{2}$ Department of Basic Science, Faculty of Physical Therapy, Beni-Suef University, Egypt \\ ${ }^{3}$ Department of Gynaecology and Obstetrics, Faculty of Medicine, Al-Azhar University, Egypt \\ ${ }^{4}$ Department of Biomechanics, Faculty of Physical Therapy, Cairo University, Egypt \\ ${ }^{5}$ Department of Physical Therapy, Faculty of Health Sciences, Beirut Arab University, Beirut, Lebanon
}

\begin{abstract}
Background: One of the many consequences of pregnancy that may negatively affect a woman's quality of life is stress urinary incontinence caused by activities of daily living especially those associated with increased intraabdominal pressure. Objective: This research aimed to explore the impact of global postural correction exercises on stress urinary incontinence among pregnant women. Participants and Methodology: Forty primigravida female at their third trimester (aged between 26-36 years), with a single fetus, diagnosed with stress urinary incontinence take part in the research. Participants were assigned randomly into two groups: Study group (group $A ; n=20$ ) and control group (group $B ; n=$ 20). The participants were tested twice, before and after a 12-week period, during which group A received global postural correction exercises in addition to Kegel exercises, while group B performed only Kegel exercises. A perineometer was used to evaluate the change in vaginal squeeze pressure both before and after conducting the study. UDI-6 was utilized to assess changes in incontinence severity symptoms. Results: Findings revealed a significant increase in the mean value of vaginal squeeze pressure $(p<.05)$ in the post-test condition in comparison to the pretest in both groups A and B. Additionally, there was a main decrease $(p<.05)$ in the mean value of UDI-6 in both groups. Moreover, findings showed a significant negative (inverse) correlation $(p<.05)$ between the difference in vaginal squeeze pressure and the UDI-6 in all patients. Conclusions: Postural correction exercises in addition to Kegel exercises are effective in reducing urine leakage in women with stress urinary incontinence and should be an integral part of the management of such condition.
\end{abstract}

Keywords: Kegel exercise; Postural correction; Stress urinary incontinence.

\section{Cite this article as:}

El Bandrawy, A.M., Mohamed, M.N., Kamal, H.A.H., Hamada, H.A., Abbas, R., \& Mohamed, M.A.E-R. (2020). Effect of global postural correction exercises on stress urinary incontinence during pregnancy: A randomized controlled trial. Journal of Human Sport and Exercise, 15(3proc), S869-S878. doi:https://doi.org/10.14198/ihse.2020.15.Proc3.38

Corresponding author. Department of Biomechanics, Faculty of Physical Therapy, Cairo University, Egypt.

E-mail: Hamada.Ahmed@pt.cu.edu.eg

Supplementary Issue: Spring Conferences of Sports Science. International Conference on Psychology of Education Sciences and Lifestyle.

JOURNAL OF HUMAN SPORT \& EXERCISE ISSN 1988-5202

(c) Faculty of Education. University of Alicante

doi:10.14198/jhse.2020.15.Proc3.38 


\section{INTRODUCTION}

Stress urinary incontinence (SUI) is the most widely recognized type of urinary incontinence (UI) during pregnancy. It presents with the symptoms of involuntary urine leakage on physical exertion, effort, and coughing or sneezing (Haylen et al., 2011). There are numerous potential risk factors for Ul including ageing, pregnancy, parity, and instrumental delivery.

Stress urinary incontinence has a high rate of $31 \%$ in nulliparous women and an even higher rate of $42 \%$ is detected in multiparous women, which increases with gestational age. Women in their third trimester show the highest prevalence, followed by those in their second trimester and then those in the first (Mørkved \& Bø, 1999). One of the physiological and anatomical changes that occur during pregnancy is pelvic floor muscle (PFM) weakness, which categorizes pregnancy as a typical risk factor for Ul, especially in the later months (Martins, Soler, Cordeiro, Amaro, \& Moore, 2010; Wijma, Weis Potters, de Wolf, Tinga, \& Aarnoudse, 2001). The growing uterus and fetus throughout pregnancy increases the stress on the PFM, which may cause PFM weakness. Additionally, PFM strength and sphincteric function are reduced due to hormonal changes during pregnancy (Mørkved, Bø, Schei, \& Salvesen, 2003), potentially causing mobility of the bladder neck and urethra which prompts inadequacy of the urethral sphincter. Any increase in intra-abdominal pressure causes intra-bladder pressure to surpass the urethral closure pressure, leading to urine leakage and inability to close the urethra due to urethral sphincter weakness (Sangsawang \& Sangsawang, 2013).

Literature review have proved that there is a relationship between postural changes, lumbo-pelvic girdle pain, and urinary incontinence among pregnant women. In the first two trimesters of pregnancy, the majority of women seem to demonstrate a swayback posture (Oliveira, Vieira, Macedo, Simpson, \& Nadal, 2009). It has been reported that postural changes caused by altered mass distribution in the spine during pregnancy as well as the presence of certain hormones are the most reported causes of SUI during pregnancy (Gilleard, Lai, Levinger, \& Begg, 2008). Proper postural alignment maintains the balance between the skeleton and muscles which reduces the stress on the body, protects the body's supportive structures, and prevents deformation during sitting and standing (Chen et al., 2008).

Pelvic floor muscle (PFM) have an essential role in reducing SUI. Pelvic floor muscle exercises are a strengthening mechanism for women suffering with SUI enhancing their self-esteem and quality of life (Ghaderi, Mohammadi, Sasan, Kheslat, \& Oskouei, 2016). PFM exercises aim at providing neuromuscular facilitation and improving endurance and strength (Senturk \& Kara, 2012). The PFMs have an essential role in reducing SUI. Since individuals with SUI typically exhibit poor posture and poor body mechanics, postural correction exercises are thought to assist with promoting proper body alignment. So, the aim of the study is to explore the effect of postural correction exercises on pregnancy related stress urinary incontinence.

\section{PARTICIPANTS AND METHODOLOGY}

\section{Participants}

A random with trial controlling, with two parallel groups with a 1:1 allocation ratio was used to assess the effect of postural correction exercises on pregnancy related SUI. Forty primigravida women with singleton fetus in their third trimester and diagnosed with pregnancy related SUI participated in this study; All women were receiving care at the Gynaecology outpatient clinic at Faculty of physical Therapy, Cairo University. They all lead a sedentary lifestyle, as they reported no involvement in any regular physical activity other than normal activities of daily living during the recruitment procedures. 
Participants' demographic data are summarized in Table 1. They were screened by the obstetrician before inclusion through full obstetric examination. The purpose and essence of the study was clarified to all participants, and informed consent was read and signed by each one.

All participants suffered from a mild to moderate grade of SUI identified by clinical grading (IngelmanSundberg) (Wlazlak, Surkont, Shek, \& Dietz, 2015) as follows: Grade I (mild), the leakage of urine occurs on straining; and grade II (moderate), the leakage occurs following abrupt movement. Females were excluded from the study if they had severe grade SUI; infections in their lower urinary tract; neurological conditions; gestational diabetes; and chronic chest diseases. Females who smoked, used any medications or medical/surgical interventions for SUI, or who suffered any other type of urinary incontinence were also excluded from the study. The Ethical Committee of the Faculty of Physical Therapy at Cairo University approved this study.

\section{Randomization}

Participants were stochastic assigned to group (A) (Kegel exercise and posture correction training) $(n=20)$ or group $(B)$ (Kegel exercise only) $(n=20)$ by an independent person who blindly selected numbers created by a random numbering generator from sealed envelopes. The randomization was limited to permuted blocks to make sure that both groups had an equal number of participants. No drop out after randomization (Figure 1).

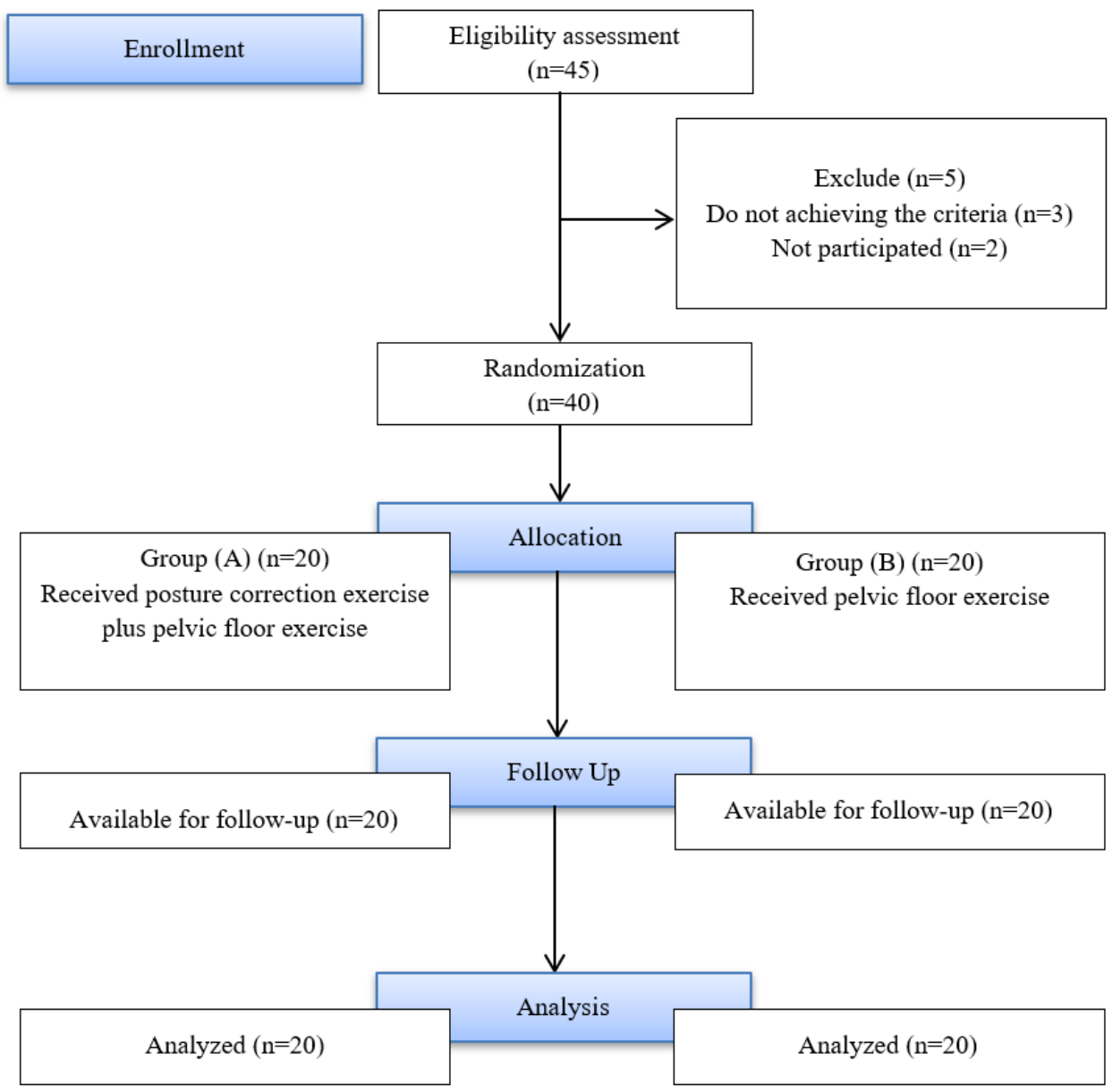

Figure 1. Flow chart demonstrates the experimental design of the study. 


\section{Outcome measures}

The change in incontinence severity symptoms (the secondary outcome) was measured through the Urogenital Distress Inventory Questionnaire (UDI-6). All outcome measures were recorded before and after treatment (after 12 weeks).

\section{Procedures and instrumentation}

Weight and height scale

Weight and height were measured for each woman. BMI is determined via dividing weight $(\mathrm{kg})$ by the height squared $\left(m^{2}\right)$.

\section{Postural correction for Group A (Park \& Park, 2003)}

\section{- $\quad$ From standing position}

Each woman was asked to stand in front of a mirror while the therapist stood beside her and instructed the following:

- Stand with your back straight and your shoulders back.

- Keep your chin tucked in.

- Take deep inspiration from your nose, open out your ribs through costal breathing.

- Lightly draw in your abdominal muscles.

- Keep your knees straight.

- Let your arms hang naturally down the sides of the body.

- Stand with your feet slightly apart (shoulder-width).

- This set was repeated 10 times

\section{- $\quad$ From sitting position}

Each woman was advised to sit well back in firm chair, support her lower back with a small pillow with legs and hips relaxed and her legs apart of the hip length.

- Pull her head straight up.

- Shoulders are pulled outwards and downwards.

- Open out her ribs through costal breathing exercise.

- Pull her abdominals towards the spine. ('abdominal bracing').

- She was advised not to sit for more than 30 minutes whenever possible.

- Avoid sitting on low stool or chair.

All postural correction exercises (in sitting and standing positions) were performed 3 times per week for 12 weeks. All women of group (A) were advised to do postural correction exercises as a home program.

Kegel Exercises for the two groups ( $A$ and $B$ )

Each participant was asked to contract the anterior fibres of the pelvic floor muscle (pubo-vaginalis), three repetitions of eight contractions (hold for 10 seconds and relax for 10 seconds) with 2 minutes rest in between. After a 2 minute rest, the subject was asked to contract the posterior fibres of the pelvic floor muscle (puborectalis), 3 repetitions of 8 contractions (hold for 30 seconds and relax for 10 seconds) with 2 minutes rest in between. The guidance for such exercise was done as follows: "A way to identify anterior pelvic floor muscles is to imagine attempting to stop urination in midstream, while identification of posterior pelvic floor muscles is to try to squeeze the anus" (Ben Ami \& Dar, 2018). Once the subject mastered the exercise and could direct her exercise towards the wanted muscles, she was advised to perform it in any position. 
After the rest time, the subject was asked to contract both posterior and anterior fibres of the pelvic floor muscles (pubo-vaginalis and pubo-rectalis), 3 repetitions of 8 contractions (hold for 30 seconds and relax for 10 seconds) with 2 minutes rest in between Kegel exercises and the session lasted for 45 minutes ( 3 times weekly, for 12 weeks) for participants in both groups ( $A$ and $B$ ). Each patient in groups $A$ and $B$ was asked to repeat her own exercise program as a home routine on the other alternate days (El Nahas, Mohamed, \& Kamal, 2017). During Kegel exercises, the participant was instructed to perform slow and deep breathing (ElBandrawy,Nashed, Hamada\& Ghareeb, 2019).

After the rest time, the subject was asked to contract both posterior and anterior fibres of the pelvic floor muscles (pubo-vaginalis and pubo-rectalis), 3 repetitions of 8 contractions (hold for 10 seconds and relax for 10 seconds) with 2 minutes rest in between Kegel exercises and the session lasted for 45 minutes ( 3 times weekly, for 12 weeks) for participants in both groups (A and B). Each patient in groups A and B was asked to repeat her own exercise program as a home routine on the other alternate days (El Nahas, Mohamed, \& Kamal, 2017). During Kegel exercises, the participant was instructed to perform slow and deep breathing.

\section{RESULTS}

\section{Regarding variables measured by Perineometer}

There were no difference for groups in PFM resting tone and squeeze vaginal pressure before treatment as measured by the perineometer. When compared to the pre-treatment condition, PFM resting tone and squeeze vaginal pressure improved in the post test condition in groups $A$ and $B$. After treatment, there was a statistically significant increase in the value of PFM resting tone and squeeze vaginal pressure in group $A$ in comparison to its corresponding value in group B as shown in Table 2.

Table 1. Patients demographic data.

\begin{tabular}{|c|c|c|c|c|}
\hline & Group $(A)(n=20)$ & Group (B) $(n=20)$ & & \\
\hline & Mean \pm SD & Mean \pm SD & t-value & $p$-value \\
\hline Age (yrs.) & $35.45 \pm 3.59$ & $35.15 \pm 3.51$ & 0.267 & $.791^{\mathrm{NS}}$ \\
\hline Height $(\mathrm{cm})$. & $161.25 \pm 3.84$ & $162.80 \pm 4.66$ & -1.148 & $.258^{\mathrm{NS}}$ \\
\hline Weight (kg.) & $74.44 \pm 7.57$ & $74.19 \pm 8.94$ & 0.095 & $.924 \mathrm{NS}$ \\
\hline $\mathrm{BMI}\left(\mathrm{kg} / \mathrm{m}^{2}\right)$ & $28.51 \pm 1.94$ & $27.82 \pm 2.00$ & 1.099 & $.279^{N S}$ \\
\hline
\end{tabular}

Table 2. Statistical analysis for pelvic floor muscle resting tone and squeeze vaginal pressure (CmH2O) values.

\begin{tabular}{llllll}
\hline & & Group A $(\mathbf{n}=\mathbf{2 0})$ & Group B $(\mathbf{n}=\mathbf{2 0})$ & $\mathbf{t}^{\#}$ value & $\mathbf{p}$-value \\
\hline \multirow{3}{*}{$\begin{array}{l}\text { Pelvic floor } \\
\text { muscle resting tone }\end{array}$} & Before treatment & $3.15 \pm 2.16$ & $2.70 \pm 2.20$ & 0.65 & $.58 \mathrm{NS}$ \\
& After treatment & $5.85 \pm 2.21$ & $4.40 \pm 1.90$ & 2.20 & $.03 \mathrm{~s}$ \\
& $\mathrm{t}^{\#}$ value & 3.70 & 2.57 & & \\
& $\mathrm{p}$-value & $.00 \mathrm{~s}$ & $.02 \mathrm{~s}$ & & \\
\hline \multirow{3}{*}{ Squeeze vaginal } & Before treatment & $36.84 \pm 7.57$ & $35.66 \pm 14.26$ & 0.330 & $.744 \mathrm{NS}$ \\
pressure & After treatment & $46.05 \pm 8.11$ & $38.10 \pm 14.79$ & 2.107 & $.044 \mathrm{~s}$ \\
& $t^{\#}$ value & -13.318 & -6.767 & & \\
& $\mathrm{p}$-value & $.014 \mathrm{~s}$ & $.001 \mathrm{~s}$ & & \\
\hline
\end{tabular}


Urogenital Distress Inventory Questionnaire (UDI-6) Pre and Post-Treatment for Both Groups A and B

In group A, there appeared to be a statistically significant decline in the value of UDI-6 measured after treatment while in comparison to its corresponding value measured before treatment. While in group $B, a$ statistically obvious reduction appeared in the mean value of UDI-6 measured after treatment when in comparison to its corresponding amount calculated before treatment. Among the groups, no statistically significant difference was noted between the mean value of UDI-6 in group A and their corresponding value in group $B$ before treatment. After treatment, there was a statistically main decrease in the value of UDI-6 in group $A$ in comparison to its corresponding value in group $B$ as shown in Table 3.

Table 3. Inter and intra-group comparison between values of UDI-6 in the two studied 12 weeks of treatment.

\begin{tabular}{lllll}
\hline & Group A $(\mathbf{n}=\mathbf{2 0})$ & Group B $(\mathbf{n}=\mathbf{2 0})$ & Z\# value & p-value \\
\hline Before treatment & $39.04(4.01)$ & $40.47(4.80)$ & -1.560 & $.119 \mathrm{NS}$ \\
After treatment & $31.10(4.01)$ & $37.24(5.13)$ & -3.574 & $.001 \mathrm{~S}$ \\
Z\#\# value & -3.921 & -3.408 & & \\
p-value & $.001 \mathrm{~S}$ & $.001 \mathrm{~s}$ & & \\
\hline
\end{tabular}

Correlation between the Difference in Squeeze Vaginal Pressure and the Difference in Urogenital Distress Inventory Questionnaire (UDI-6)

There is a main negative (inverse) correlation between the difference in squeeze vaginal pressure and UDI6 in all patients $(n=40)(\rho=-.640 ; p=.001)$. There is a direct link between the difference in squeeze vaginal pressure and UDI-6 in all patients $(n=40)$.

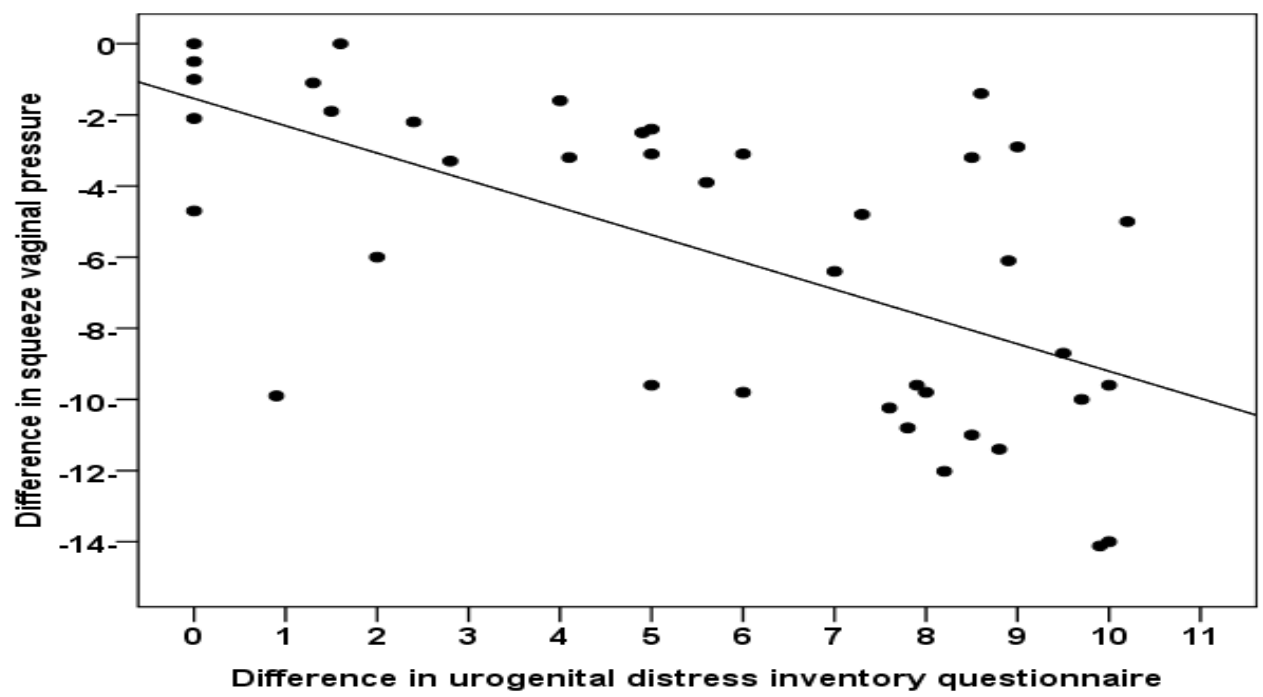

Figure 2. Correlation between the difference in squeeze vaginal pressure and Urogenital Distress Inventory Questionnaire (UDI-6) in all patients.

\section{DISCUSSION}

Most pregnant women suffer from stress urinary incontinence (SUI) which dramatically influences their quality of life. In addition, other morbid conditions after giving birth worsen personal and general health (Dolan et al., 2004). 
Postural changes have been shown to be one of the causes of SUI in pregnant women (Manshadi, Ghanbari, Miri, \& Azimi, 2016) found a significant change in the pelvic inclination angle. In the same context, participants generated more electromyographic activity (EMG) of the PFM in their regular posture than in their hypo or hyperlordotic postures. This clearly indicated that changes in lumbo-pelvic postures affected the PFM contractility and vaginal pressure in static positions and during dynamic activities (Capson, Nashed, \& McLean, 2011).

Incorrect position of the pelvis can lead to morphological alterations in the placement of the bladder neck and proximal part of the urethra with respect to the urogenital diaphragm and other surrounding structures (Mørkved et al., 2003). A healthy woman's urethra extends downward through the urogenital diaphragm. During correct pelvic posture, the urethra is placed obliquely, anterior and inferior, nearly vertically which aids in urine free flow during sphincter relaxation. The closing force generated by the PFM is much greater when the urethra is more perpendicular to the pelvic floor (Taradaj et al., 2008).

In physiotherapy practice, much attention is directed towards the relationship between the pelvis and its adjacent structures. However, the literature reveals only basic information about their common connections (Cerruto, Vedovi, Mantovani, D'Elia, \& Artibani, 2012). Despite of the lack of information and the scarcity of scientific literature on the effect of postural correction exercises on the pelvic floor and stress urinary incontinence, the authors tried to explain whether postural correction exercises could influence PFM activity and decrease stress urinary incontinence during pregnancy.

The findings of research showed a significant improvement in group A who were treated by postural correction training. These results are approved by others (Ptaszkowski et al., 2017), who stated that postural changes were an efficient way of minimizing urine leakage among female complaining from SUI and should become an essential part of managing this condition.

Posterior pelvic tilt position, reinforced by postural correction exercises, provides greater functional and resting bioelectric activity of the PFM. In addition, PFM electromyographic activity increases during backward movement of the pelvis (Ptaszkowski et al., 2017). Even though hamstring are essential part in addressing anterior pelvic tilt, however training them was not performed to make exercise application easier for the subject and the assumption done was that training antagonist muscles eventually provokes facilitation of agonist muscles through spinal mechanisms. It was stated that in loading knee joint in bilateral standing and squatting produce poor but present hamstring/quadriceps co-activation ratios (Dedinsky, Baker, Imbus, Bowman, \& Murray, 2017). These results can be explained by the fact that postural awareness eventually did provoke an overall facilitation in order to improve stress incontinence related outcome measures, however the extent of effect must be further investigated.

Results of the present research also revealed a significant improvement in group $B$ who were treated by Kegel exercise and this was supported by (Sangsawang \& Sangsawang, 2013) who stated that the pelvic floor muscle exercises program, supervised for 6 weeks, decreased the severity of SUI in women who were pregnant and who reported SUI at the end of their pregnancy. The urinary incontinence frequencies were reduced to less than $30 \%$. Therefore, Kegel exercises were proven to be an effective method to improve SUI. One of the challenges faced during application was the commitment of pregnant women to perform such kind of exercises.

Exercising the levator ani (LA) muscle could increase its compression. Taking into consideration that the LA muscle is composed of type I and type II muscle fibres, certain strengthening exercises can change the size 
of type II muscle fibres through hypertrophy. Thus, resistive training of LA type II muscle fibres could help the urethral sphincter in controlling continence (Cammu, Van Nylen, Blockeel, Kaufman, \& Amy, 2004). Strong contraction of the LA will enhance closure of the urethra and support of the pelvic organ. Urethral compression by properly timed and sufficient pelvic floor muscle contraction will stop leakage of urine (Prather, Dugan, Fitzgerald, \& Hunt, 2009).

The findings of the current research were supported by others (Mørkved et al., 2003) who stated that the striated sphincter of the urethra automatically contracts while the PFMs are contracted voluntarily. This result suggests that PFM training can enhance striated urethral sphincter function and volume.

\section{Limitations}

Weight and BMI were only assessed before starting the exercises in order to confirm homogeneity of the sample, any variation throughout the study in regards of these variables was not evaluated. Additionally, some exercises were assumed to be done correctly by the participant especially Kegel exercises. Additionally, the exercises done at home were not supervised however women were instructed to do them carefully in order not to do any harm. Finally, the same testers did the outcome measures before and after the study completion, however they were not aware of the allocation of study participants in groups. Postural correction exercises in addition to Kegel exercises are effective.

\section{REFERENCES}

Alvim, F. C., Peixoto, J. G., Vicente, E. J., Chagas, P. S., \& Fonseca, D. S. (2010). Influences of the extensor portion of the gluteus maximus muscle on pelvic tilt before and after the performance of a fatigue protocol. Rev Bras Fisioter, 14(3), 206-213.

Bai, S. W., Kang, J. Y., Rha, K., Lee, M. S., Kim, J. Y., \& Park, K. H. (2002). Relationship of urodynamic parameters and obesity in women with stress urinary incontinence. The Journal of reproductive medicine, 47(7), 559-563.

Ben Ami, N., \& Dar, G. (2018). What is the most effective verbal instruction for correctly contracting the pelvic floor muscles? Neurourology and urodynamics, 37(8), 2904-2910. https://doi.org/10.1002/nau.23810

Cammu, H., Van Nylen, M., Blockeel, C., Kaufman, L., \& Amy, J. J. (2004). Who will benefit from pelvic floor muscle training for stress urinary incontinence? Am J Obstet Gynecol, 191(4), 1152-1157. https://doi.org/10.1016/j.ajog.2004.05.012

Capson, A. C., Nashed, J., \& McLean, L. (2011). The role of lumbopelvic posture in pelvic floor muscle activation in continent women. $J$ Electromyogr Kinesiol, 21(1), 166-177. https://doi.org/10.1016/j.jelekin.2010.07.017

Cerruto, M., Vedovi, E., Mantovani, W., D'Elia, C., \& Artibani, W. (2012). Effects of ankle position on pelvic floor muscle electromyographic activity in female stress urinary incontinence: preliminary results from a pilot study. Archivio italiano di urologia, andrologia: organo ufficiale [di] Societa italiana di ecografia urologica e nefrologica, 84(4), 184-188.

Chen, K. M., Chen, M. H., Hong, S. M., Chao, H. C., Lin, H. S., \& Li, C. H. (2008). Physical fitness of older adults in senior activity centres after 24-week silver yoga exercises. J Clin Nurs, 17(19), 26342646. https://doi.org/10.1111/j.1365-2702.2008.02338.x

Dedinsky, R., Baker, L., Imbus, S., Bowman, M., \& Murray, L. (2017). Exercises that facilitate optimal hamstring and quadriceps co-activation to help decrease acl injury risk in healthy females: a systematic review of the literature. Int J Sports Phys Ther, 12(1), 3-15. 
Dolan, L. M., Walsh, D., Hamilton, S., Marshall, K., Thompson, K., \& Ashe, R. G. (2004). A study of quality of life in primigravidae with urinary incontinence. Int Urogynecol J, 15(3), 160-164. https://doi.org/10.1007/s00192-004-1128-x

El-Bandrawy, A. M., Nashed, A. B., Hamada, A. H.\& Ghareeb, H. A.(2019). Effect of diaphragmatic breathing exercises and pelvic floor retraining on postmenopausal stress urinary incontinence: $A$ randomized controlled trail. Fizjoterapia polska, 2, 60-64.

El Nahas, E. M., Mohamed, M. A., \& Kamal, H. M. (2017). Postnatal rehabilitation of pelvic floor muscles using aerobic and Kegel exercises. Bulletin of Faculty of Physical Therapy, 22(2), 67.

Ghaderi, F., Mohammadi, K., Sasan, R. A., Kheslat, S. N., \& Oskouei, A. E. (2016). Effects of stabilization exercises focusing on pelvic floor muscles on low back pain and urinary incontinence in women. Urology, 93, 50-54. https://doi.org/10.1016/j.urology.2016.03.034

Gilleard, W., Lai, D. T., Levinger, P., \& Begg, R. K. (2008). Detecting trunk motion changes due to pregnancy using pattern recognition techniques. Paper presented at the 2008 30th Annual International Conference of the IEEE Engineering in Medicine and Biology Society. https://doi.org/10.1109/iembs.2008.4649684

Hannestad, Y. S., Rortveit, G., Daltveit, A. K., \& Hunskaar, S. (2003). Are smoking and other lifestyle factors associated with female urinary incontinence? The Norwegian EPINCONT Study. BJOG: An International Journal of Obstetrics \& Gynaecology, 110(3), 247-254. https://doi.org/10.1046/j.14710528.2003.02327.x

Haylen, B. T., Freeman, R. M., Swift, S. E., Cosson, M., Davila, G. W., Deprest, J., . . Webb, R. J. (2011). An International Urogynecological Association (IUGA) / International Continence Society (ICS) joint terminology and classification of the complications related directly to the insertion of prostheses (meshes, implants, tapes) \& grafts in female pelvic floor surgery. Int Urogynecol J, 22(1), 3-15. https://doi.org/10.1007/s00192-010-1324-9

Manshadi, F. D., Ghanbari, Z., Miri, E.-S., \& Azimi, H. (2016). Postural and musculoskeletal disorders in women with urinary incontinence: A research report. Journal of Clinical Physiotherapy Research, 1(1), 27-31.

Martins, G., Soler, Z. A., Cordeiro, J. A., Amaro, J. L., \& Moore, K. N. (2010). Prevalence and risk factors for urinary incontinence in healthy pregnant Brazilian women. Int Urogynecol J, 21(10), 1271-1277. https://doi.org/10.1007/s00192-010-1185-2

Mørkved, S., \& Bø, K. (1999). Prevalence of urinary incontinence during pregnancy and postpartum. Int Urogynecol J, 10(6), 394-398. https://doi.org/10.1007/s001920050067

Mørkved, S., Bø, K., Schei, B., \& Salvesen, K. Å. (2003). Pelvic floor muscle training during pregnancy to prevent urinary incontinence: a single-blind randomized controlled trial. Obstetrics \& Gynecology, 101(2), 313-319. https://doi.org/10.1097/00006250-200302000-00018

Oliveira, L. F., Vieira, T. M., Macedo, A. R., Simpson, D. M., \& Nadal, J. (2009). Postural sway changes during pregnancy: a descriptive study using stabilometry. European Journal of Obstetrics \& Gynecology and Reproductive Biology, 147(1), 25-28. https://doi.org/10.1016/j.ejogrb.2009.06.027

Park, M. J., \& Park, J. S. (2003). Effect of a posture training program on cobb angle and knowledge of posture of elementary school students. Journal of Korean Academy of Nursing, 33(5), 643-650. https://doi.org/10.4040/jkan.2003.33.5.643

Prather, H., Dugan, S., Fitzgerald, C., \& Hunt, D. (2009). Review of anatomy, evaluation, and treatment of musculoskeletal pelvic floor pain in women. Pm r, 1(4), 346-358. https://doi.org/10.1016/j.pmri.2009.01.003

Ptaszkowski, K., Zdrojowy, R., Slupska, L., Bartnicki, J., Dembowski, J., Halski, T., \& Paprocka-Borowicz, M. (2017). Assessment of bioelectrical activity of pelvic floor muscles depending on the orientation 
of the pelvis in menopausal women with symptoms of stress urinary incontinence: continued observational study. Eur J Phys Rehabil Med, 53(4), 564-574.

Sangsawang, B., \& Sangsawang, N. (2013). Stress urinary incontinence in pregnant women: a review of prevalence, pathophysiology, and treatment. Int Urogynecol J, 24(6), 901-912. https://doi.org/10.1007/s00192-013-2061-7

Senturk, S., \& Kara, M. (2012). Risk factors and prevalence of urinary incontinence in postmenopausal women living in Turkey. Clin Exp Obstet Gynecol, 39(1), 69-71.

Taradaj, J., Franek, A., Brzezinska-Wcislo, L., Cierpka, L., Dolibog, P., Chmielewska, D., . . Kusz, D. (2008). The use of therapeutic ultrasound in venous leg ulcers: a randomized, controlled clinical trial. Phlebology, 23(4), 178-183. https://doi.org/10.1258/phleb.2008.008015

Wijma, J., Weis Potters, A. E., de Wolf, B. T., Tinga, D. J., \& Aarnoudse, J. G. (2001). Anatomical and functional changes in the lower urinary tract during pregnancy. Bjog, 108(7), 726-732. https://doi.org/10.1111/j.1471-0528.2001.00123.x

Wlazlak, E., Surkont, G., Shek, K. L., \& Dietz, H. P. (2015). Can we predict urinary stress incontinence by using demographic, clinical, imaging and urodynamic data? Eur J Obstet Gynecol Reprod Biol, 193, 114-117. https://doi.org/10.1016/j.ejogrb.2015.07.012

\section{(9) $\odot \Theta \Theta$}

This work is licensed under a Attribution-NonCommercial-NoDerivatives 4.0 International (CC BY-NC-ND 4.0). 